\title{
Pengembangan Perangkat Pembelajaran Model Problem Based Learning pada Matakuliah Filologi Berbasis Budaya "Aksara Mbojo" untuk Mengembangkan Kreativitas Mahasiswa
}

\author{
Lili Suryaningsih", Sandi Achmad Pratama² \\ ${ }^{1}$ Program studi Pendidikan Bahasa dan Sastra Indonesia, STKIP Yapis Dompu \\ 2 Program studi Pendidikan Jasmani Kesehatan dan Rekreasi, STKIP Yapis Dompu \\ E-mail: liliedaelilu@gmail.com
}

\begin{tabular}{|c|c|}
\hline Article Info & Abstract \\
\hline $\begin{array}{l}\text { Article History } \\
\text { Received: } 2021-07-12 \\
\text { Revised: } 2021-08-15 \\
\text { Published: } 2021-10-17\end{array}$ & $\begin{array}{l}\text { This research is a development research that aims to develop learning tools which } \\
\text { include: Textbooks, lesson plans, worksheets and instruments to measure students' } \\
\text { creative thinking skills that refer to the 4-D model (Define, Design, Develop, and } \\
\text { Disseminate). Based on the results of research conducted through descriptive analysis, } \\
\text { that the learning tool for the Philology course "Scripture" which was developed to } \\
\text { Train students' Creative Thinking Ability was in the "very good" category, this was } \\
\text { indicated by the fulfillment of six criteria for proper learning tools, including (a) Valid } \\
\text { according to the validator, (b) Effective on the ability of researchers/lecturers in } \\
\text { managing learning, (c) Effective for student activities in learning, (d) Positive on } \\
\text { student responses to learning, (e) Valid, reliable, and sensitive to THB, and ( f) the } \\
\text { achievement of classical learning completeness. }\end{array}$ \\
\hline Artikel Info & Abstrak \\
\hline $\begin{array}{l}\text { Sejarah Artikel } \\
\text { Diterima: } 2021-07-12 \\
\text { Direvisi: } 2021-08-15 \\
\text { Dipublikasi: } 2021-10-17\end{array}$ & $\begin{array}{l}\text { Penelitian ini merupakan penelitian pengembangan yang bertujuan untuk } \\
\text { mengembangkan perangkat pembelajaran yang meliputi: Buku teks, RPS, LKS serta } \\
\text { instrumen untuk mengukur kemampuan berpikir kreatif mahasiswa yang mengacu } \\
\text { pada model 4-D (Define, Design, Develop, dan Desiminasi). Berdasarkan hasil } \\
\text { penelitian yang dilakukan melalui analisis deskriptif, bahwa perangkat pembelajaran } \\
\text { matakuliah Filologi "Naskah Aksara" yang dikembangkan untuk Melatih Kemampuan } \\
\text { Berpikir Kreatif mahasiswa mendapat kategori "sangat baik", hal ini ditunjuk oleh } \\
\text { terpenuhnya enam kriteria perangkat pembelajaran yang layak, meliputi (a) Valid } \\
\text { menurut validator, (b) Efektif atas kemampuan Peneliti/Dosen dalam mengelola } \\
\text { pembelajaran, (c) Efektif bagi mahasiswa kegiatan dalam pembelajaran, (d) Positif } \\
\text { terhadap respon siswa terhadap pembelajaran, (e) Valid, reliabel, dan peka terhadap } \\
\text { THB, serta (f) tercapainya ketuntasan belajar secara klasikal. }\end{array}$ \\
\hline
\end{tabular}

\section{PENDAHULUAN}

Dalam mengembangkan kualitas pendidikan nasional yang baik, Indonesia perlu meningkatkan Sumber Daya Manusia (SDM), mengingat aspek tersebut merupakan salah satu aspek yang memberikan kontribusi sangat signifikan terhadap pencapaian tujuan pendidikan nasional. Oleh karena itu, diperlu-kanya tenaga pendidik/ Dosen profesional sebagai fasilitator dalam memfasilitasi para mahasiswa untuk melatih pemahaman berpikir kritis maupun kreativitas mahasiswa. Nurdin \& Sibaweh, dalam (Nurochmah et al., 2019), mengemukakan bahwa pengembangan profesi-onal merupakan suatu aktivitas atau proses pengawasan yang bertujuan untuk memperbaiki skill, sikap, pemahaman atau performance yang berperan untuk sekarang hingga masa yang akan datang. Pengembangan professional suatu keharusan bagi tenaga Pendidik/ Dosen agar dapat mengikuti perubahan dan perkembangan yang terjadi pada teknologi dan struktur dalam pembelajaran mahasiswa, salah satunya ialah dengan cara mengembangkan sebuah perangkat pembelaja-ran yang berkualitas baik.

Perangkat pembelajaran yang berkualitas baik adalah perangkat pembelajaran yang dikembangkan sesuai dengan prosedur pengembangan perangkat serta memenuhi kategori-kategori: 1) Valid berdasarkan penilaian para ahli/pakar, 2) Efektif untuk aktivitas mahasiswa yaitu apabila waktu yang digunakan untuk melakukan setiap aspek aktivitas sesuai dengan alokasi waktu yang termuat setiap RPS dengan toleransi 10\%, 3) Efektif untuk kemampuan dosen mengelola pembelajaran, yaitu jika rata-rata skor dari setiap aspek yang dinilai untuk setiap RPS berada pada kategori minimal baik, 4) Positif untuk respon mahasiswa terhadap pembelajaran, 5) Validitas butir tes, reliabilitas tes, dan sensitivitas butir tes, 
dan 6) Ketuntasan belajar adalah pencapaian tujuan pembelajaran tertentu yang ditunjukkan oleh penguasaan atau daya serap terhadap materi pembelajaran tertentu. Mahasiswa dikatakan tuntas belajarnya secara individu jika mahasiswa tersebut memiliki daya serap paling sedikit 70\%.Sedangkan, ketuntasan belajar mahasiswa secara klasikal dicapai apabila paling sedikit 85\% mahasiswa di kelas tersebut tuntas belajarnya. Taufik (2020)

Dari Hal tersebut, Penulis ingin mengembangkan sebuah perangkat pembelajaran Model Problem Based Learning berbasis budaya lokal "Aksara Mbojo" yang merupakan aksara daerah Kabupaten Bima sebuah sistem tanda grafis yang digunakan manusia untuk berkomunikasi sedikit banyaknya mewakili ujaran melalui tulisan. Pembelajaran Program Based Learning merupakan susunan kegiatan pembelajaran yang bertumpu pada pemecahan masalah dengan cara ilmiah. Pembantu siswa untuk mengembangkan keterampilan untuk belajar secara mandiri, keterampilan penyelidikan dan keterampilan mengatasi masalah serta perilaku dan keterampilan sosial sesuai peran orang dewasa. Kamdi,(dalam (Hutabara et al., 2020)).

Sehubungan dengan penggunaan budaya lokal "Aksara Mbojo", pemerintah telah mengatur tentang Perlindungan kebudayaan daerah, dalam RUU Nomer 5 Tahun 2017 yang menyatakan bahwa "Kebudayaan telah menjadi akar dari pendidikan. Oleh karena itu, RUU Pemajuan Kebudayaan perlu menekankan pada perlindungan, pengembangan, pemanfaatan, dan pembinaan agar budaya Indonesia dapat tumbuh dan berkembang (Taufik, Erwin, 2020). Berdasarkan uraian di atas, maka peneliti tertarik untuk Mengembangkan Pembelajaran Berbasis Budaya "Aksara Mbojo" Menggunakan Model Problem Based Learning untuk Mengembangkan Kreativitas Mahasiswa Bahasa dan sastra Indonesia.

\section{METODE PENELITIAN}

Penelitian ini merupakan penelitian pengembangan (developmental research), dengan mengembangkan perangkat pembela- jaran yang meliputi: RPS, LKM, Buku Ajar serta instrument kemampuan berpikir kreatif mahasiswa yang mengacu pada model Problem Based Learning, Penelitian ini dilaksanakan di Mahasiswa Program Studi Pendidikan Bahasa dan Sastra Indonesia Semester V dengan jumlah 28 Orang Mahasiswa, tahun pembelajaran 2020/2021, Pengembangan yang akan digunakan untuk mengembangkan perangkat pembelajaran dalam penelitian ini adalah model Thiagaraja yang dikenal dengan Four- $D$ Models (Model 4-D) dalam (Taufik, Erwin, 2020). Instrument penelitian yang digunakan dalam penelitian ini yaitu:

a. Lembar Validasi Perangkat Pembelajaran

Lembar validasi perangkat pembelajaran terdiri dari lembar validasi RPS, lembar validasi Work Sheet, lembar validasi Tes Kemampuan Berpikir Kreatif, lembar validasi Buku Ajar

b. Sheet Work

Sheet Work digunakan untuk memperoleh informasi berkaitan dengan kegiatan belajar mahasiswa selama uji coba.

c. Lembar observasi kemampuan dosen mengelola pembelajaran

Instrumen ini digunakan untuk mengamati beberapa aspek kemampuan dosen, yang berkaitan dengan tahapan model Problem Based Learning

d. Angket respon mahasiswa

Respon mahasiswa adalah tanggapan mahasiswa setelah diterapkan perangkat pembelajaran menggunakan Problem Based Learning untuk meningkatkan kreativitas mahasiswa.

e. Tes Hasil Belajar

Tes Hasil Belajar digunakan untuk memperoleh informasi tentang hasil belajar secara klasikal. Bentuk tes adalah uraian dan penilaian bergantung pada kesulitan soal. Agar tes yang disusun berkualitas memadai, maka diperlukan analisis butir. Analisis butir tes meliputi uji validitas, uji reliabilitas, dan uji sensitivitas.

\section{HASIL DAN PEMBAHASAN}

A. Deskripsi Hasil Validitas Perangkat Pembelajaran

1. Hasil Validitas Rencana Pembelajaran Semester

Hasil validasi rencana pelaksanaan pembelajaran yang diberikan kepada validator menunjukkan bahwa rata-rata penilaian setiap indikator untuk semua aspek berada pada kategori sangat baik, sehingga dapat dinyatakan bahwa RPS dalam draft 1 bernilai valid. Secara umum, validator menyatakan bahwa RPS bernilai sangat baik dan dapat digunakan dengan revisi kecil, Revisi dilakukan berdasarkan saran-saran validator, seperti alokasi waktu yang diberikan untuk setiap kegiatan pembelajaran. 
2. Hasil Validasi Work Sheet

Hasil validasi ahli yang telah dilakukan menunjukkan bahwa rata-rata setiap indikator pada semua aspek yang dinilai berada pada kategori baik dan sangat baik. Hasil penilaian secara umum terhadap work sheet menunjukkan bahwa berkualitas sangat baik. Sehingga dapat digunakan dengan sedikit revisi, Revisi yang dilakukan sesuai dengan saran-saran validator, seperti perbaikan penggunaan bahasa serta perbesaran ukuran gambar dan kejelasan warna gambar.

3. Hasil Validasi Instrumen Tes Hasil Belajar (THB)

Hasil validasi ahli yang telah dilakukan menunjukkan bahwa, rata-rata setiap indikator pada semua aspek yang dinilai berada pada kategori baik dan sangat baik. Hasil penilaian secara umum terhadap THB yang menunjukkan bahwa THB berkualitas sangat baik sehingga dapat digunakan dengan sedikit revisi.

4. Hasil Validasi Angket Respon Mahasiswa Hasil validasi ahli yang telah dilakukan menunjukkan bahwa rata-rata setiap indikator pada semua aspek yang dinilai berada pada kategori baik dan sangat baik. Hasil penilaian secara umum terhadap angket respon mahasiswa menunjukkan bahwa angket respon mahasiswa berkualitas sangat baik sehingga dapat digunakan dengan revisi kecil.

B. Uji coba Perangkat Pembelajaran

Uji coba lapangan dilakukan untuk memperoleh data atau masukan dari dosen, mahasiswa, dan para pengamat (observer) terhadap semua perangkat pembelajaran yang telah disusun sebagai dasar untuk melakukan revisi (penyempurnaan) draft III menjadi draft final.

1) Hasil penilaian kemampuan dosen mengelola pembelajaran

Berdasarkan kategori kemampuan dosen mengelola pembelajaran seperti yang diuraikan pada bagian sebelumnya mengindikasikan bahwa pembelajaran efektif. Hasil ini diperoleh karena rata-rata skor setiap aspek kemampuan dosen mengelola pembelajaran yang dinilai pada setiap RPS mencapai kategori minimal "baik".

2) Hasil pengamatan aktivitas mahasiswa selama pembelajaran

Jumlah mahasiswa yang diamati 4 orang, yaitu 1 orang dari kelompok atas, 2 orang dari kelompok tengah, dan 1 orang dari kelompok bawah. Pengamatan dilakukan oleh satu orang, Berdasarkan kriteria keefektifan aktivitas mahasiswa yang telah diuraikan pada bagian sebelumnya, menunjukkan bahwa uji coba ini dikategorikan efektif. Hal ini dikarenakan hasil pengamatan menunjukkan bahwa setiap aspek aktivitas mahamahasiswa untuk semua rencana pelaksanaan pembelajaran (RPS) berada pada interval kriteria batas toleransi waktu ideal.

3) Hasil angket respon mahasiswa

Seperti yang telah diuraikan pada pembahasan sebelumnya bahwa Respon mahasiswa dikategorikan positif jika mahasiswa memilih aspek positif atau aspek negatif yang tertera pada angket dengan persentase $\geq 70 \%$. Untuk aspek yang persentasenya kurang dari $70 \%$ maka akan digunakan sebagai dasar untuk merevisi perangkat pembelajaran, Hasil pengukuran menunjukkan bahwa respon mahasiswa terhadap pembelajaran dengan model based learning lebih dari 70\% mahasiswa memberikan respon dengan kategori positif.

4) Hasil uji coba tes hasil belajar (THB)

Tujuan dari uji coba THB adalah untuk memperoleh data tentang validitas butir tes, reliabilitas tes, dan sensitivitas butir tes, ketiga indikator ini merupakan penentu keputusan apakah tes yang dikembangkan perlu direvisi atau tidak. Hasil analisis validitas butir tes, reliabilitas tes, dan sensitifitas butir tes sebagai berikut:

a. Validitas

Berdasarkan rumus korelasi product moment diperoleh validitas setiap butir tes sebagai berikut:

Tabel 1. Hasil Analisis Butir Tes

\begin{tabular}{|c|c|c|c|c|c|c|c|}
\hline No Soal & $1 \mathrm{a}$ & $1 \mathrm{~b}$ & $2 a$ & 2b & $2 c$ & $3 a$ & $3 b$ \\
\hline $\mathrm{r}_{\mathrm{xy}}$ & 0,61 & 0,67 & 0,63 & $\begin{array}{c}0,5 \\
8 \\
\end{array}$ & $\begin{array}{c}0,4 \\
7 \\
\end{array}$ & $\begin{array}{c}0,6 \\
8 \\
\end{array}$ & $\begin{array}{c}0,4 \\
3 \\
\end{array}$ \\
\hline $\begin{array}{l}\text { Interpret } \\
\text { asi }\end{array}$ & $\begin{array}{c}\text { Ting } \\
\text { gi }\end{array}$ & $\begin{array}{c}\text { Ting } \\
\text { gi }\end{array}$ & $\begin{array}{c}\text { Ting } \\
\text { gi }\end{array}$ & $\begin{array}{c}\text { Cuk } \\
\text { up } \\
\end{array}$ & $\begin{array}{c}\text { Cuk } \\
\text { up } \\
\end{array}$ & $\begin{array}{l}\text { Tin } \\
\text { ggi }\end{array}$ & $\begin{array}{l}\text { Tin } \\
\text { ggi }\end{array}$ \\
\hline No Soal & $4 a$ & $4 \mathrm{~b}$ & $4 \mathrm{c}$ & $4 \mathrm{~d}$ & $4 \mathrm{e}$ & \multicolumn{2}{|c|}{$4 \mathrm{f}$} \\
\hline $\mathrm{r}_{\mathrm{xy}}$ & 0,47 & 0,55 & 0,42 & 0,44 & 0,53 & \multicolumn{2}{|c|}{0,44} \\
\hline $\begin{array}{l}\text { Interpret } \\
\text { asi }\end{array}$ & $\begin{array}{l}\text { Cuk } \\
\text { up }\end{array}$ & $\begin{array}{c}\text { Cuk } \\
\text { up }\end{array}$ & $\begin{array}{l}\text { Cuk } \\
\text { up }\end{array}$ & $\begin{array}{l}\text { Cuk } \\
\text { up }\end{array}$ & $\begin{array}{l}\text { Cuk } \\
\text { up }\end{array}$ & \multicolumn{2}{|c|}{ Cukup } \\
\hline
\end{tabular}

Berdasarkan Tabel di atas, validitas dari masing-masing butir soal THB berada pada kategori cukup dan tinggi. Dengan demikian semua butir soal THB valid.

b. Reliabilitas

reliabilitas tes menunjukkan koefisien reliabilitas sebesar 0,87. Angka ini 
menunjukkan bahwa reliabilitas instrumen THB termasuk dalam kategori "tinggi". Dengan demikian, instrumen THB dapat dikatakan reliabel

c. Sensitivitas

Ensitivitas tes menunjukkan bahwa setiap butir tes sensitif terhadap pembelajaran. Berdasarkan hasil analisis validitas butir tes, reliabilitas tes, dan sensitivitas butir tes. Maka, THB dapat dikategorikan baik

d. Hasil Belajar dan Ketuntasan belajar Hasil belajar yang ditunjukkan oleh nilai postes pada saat uji coba adalah sebagai berikut:

Tabel 2. Nilai tes hasil belajar

\begin{tabular}{cc}
\hline Nilai & Postes \\
\hline Tertinggi & 30 \\
\hline Terendah & 14 \\
\hline Rata-rata & 22,35 \\
\hline
\end{tabular}

Seperti yang telah diuraikan pada pembahasan sebelumnya, bahwa belajar mahasiswa dikatakan tuntas secara individual, jika skor postes yang diperoleh paling sedikit $70 \%$ dari skor tertinggi, yaitu 30. Sedangkan suatu kelompok (kelas) dikatakan tuntas belajarnya secara klasikal jika 85\% mahasiswa tuntas secara individual, Ketuntasan belajar mahasiswa baik secara individual maupun secara klasikal ditunjukkan dalam berikut:

Tabel 3. Ketuntasan hasil belajar

\begin{tabular}{ll}
\hline \multicolumn{1}{c}{ Postes } & \multicolumn{1}{c}{ Uji coba } \\
\hline $\begin{array}{l}\text { Banyaknya mahasiswa } \\
\text { yang tuntas secara } \\
\text { individu }\end{array}$ & $\begin{array}{l}23 \text { mahasiswa atau } \\
85 \%\end{array}$ \\
\hline $\begin{array}{l}\text { Banyaknya mahasiswa } \\
\text { yang tidak tuntas secara } \\
\text { individu }\end{array}$ & $\begin{array}{l}3 \text { mahasiswa atau } \\
15 \%\end{array}$ \\
\hline $\begin{array}{l}\text { Ketuntasan belajar } \\
\text { secara klasikal }\end{array}$ & Tuntas \\
\hline
\end{tabular}

Hasil penilaian ahli/ validator seperti yang diuraikan pada Bab III menunjukkan bahwa, perangkat pembelajaran yang terdiri dari: RPS, work sheet, dan THB ditinjau dari indikator format, bahasa, isi, dan/atau ilustrasi dikategorikan baik. Hal ini ditunjukkan dengan rata-rata skor penilaian ahli terhadap RPS, work sheet, dan THB lebih dari 3,50. Secara umum, perangkat pembelajaran filologi dengan model problem based learning di di kampus yang dikembangkan berada pada kategori"sangat baik" dan dapat digunakan dengan sedikit revisi. Jadi, secara keseluruhan perangkat pembelajaran filologi berbasis budaya "aksara mbojo"dengan pendekatan based learning di kampus baik menurut penilaian ahli, Berdasarkan kategori kemampuan dosesn mengelola pembelajaran seperti yang diuraikan pada pembahasan sebelumnya, hasil analisis data setiap aspek kemampuan dosen mengelola pembelajaran yang diamati/dinilai untuk 4 pertemuan mengindikasikan bahwa pembelajaran efektif. Hal ini ditunjukkan dengan rata-rata skor setiap aspek kemampuan dosen mengelola pembelajaran mencapai kategori minimal baik.

Pembelajaran filologi aksara dengan model based learning di kampus mengharuskan mahasiswa untuk aktif dalam pembelajaran. Sehingga, dominasi dosen dapat berkurang. Hal ini sejalan dengan Teori Konstruktivis dimana teori ini menganjurkan agar mahasiswa lebih berperan aktif dalam pembelajaran atau yang lebih dikenal dengan pembelajaran yang berpusat pada mahasiswa. Hasil analisis data aktivitas mahasiswa menunjukkan bahwa, persentase aktivitas mahasiswa dari setiap aspek yang diamati selama 4 pertemuan sesuai dengan alokasi waktu dalam RPS dan sesuai dengan kriteria waktu ideal, Berdasarkan kriteria keefektifan aktivitas mahasiswa seperti yang telah diuraikan pada Bab III, menunjukkan bahwa Aspek ke-1 tentang "Memperhatikan/ mencatat/ bertanya/ menjawab penjelasan atau pertanyaan dari dosen saat orientasi dan pembekalan" untuk semua RPS berada padakriteria waktu ideal. Aspek ke-2 tentang "menyelesaikan work sheet secara individu" untuk semua RPS berada pada kriteria waktu ideal. Aspek ke-3 tentang "menyelesaikan work sheet melalui diskusi kelompok" untuk semua RPS berada padakriteria waktu ideal. Aspek ke-4 tentang "berperan serta dalam kegiatan presentasi" untuk semua RPS berada pada kriteria waktu ideal. Aspek ke-5 tentang "mengikuti penarikan kesimpulan" untuk semua RPS berada pada kriteria waktu ideal. Aspek ke-6 tentang "prilaku yang tidak relevan" untuk semua RPS berada padakriteria waktu ideal. Berdasarkan data di atas dapat disimpulkan bahwa aktivitas mahasiswa dikategorikan "efektif", hasil analisis data respon mahasiswa terhadap komponen dan kegiatan pembelajaran filologi dengan pendekatan based learning menunjukkan lebih dari $70 \%$ mahasiswa memberikan respon dengan kategori "positif" untuk tiap-tiap aspek, hasil analisis validitas butir tes, reliabilitas tes, dan sensitivitas butir tes menunjukkan bahwa semua butir tes hasil 
belajar topik logika memiliki validitas cukup dan tinggi, hal ini sejalan dengan yang dikemukakan Arikunto bahwa suatu butir dinyatakan valid jika koefisien validitas butir tersebut diinterpretasikan minimal cukup. Reliabilitas tes hasil belajar termasuk dalam kategori tinggi, dan semua butir tes sensitif terhadap pembelajaran. hal ini juga sejalan dengan yang dikemukakan Ratumanan dan Laurens bahwa suatu tes ddinyatakan reliabel jika koefisien reliabilitas tes tersebut diinterpretasikan minimal cukup dan suatu butir tes dikatakan sensitif apabila indeks sensitivitasnya berada antara 0,00 dan 1,00. Sehingga THB dikategorikan "baik".

Berdasarkan kriteria ketuntasan hasil belajar yang telah diuraikan pada bagian sebelumnya, ketuntasan belajar mahasiswa secara individual mencapai 23 mahasiswa atau 85\% mahasiswa tuntas secara individual. Oleh karena itu, ketuntasan belajar mahasiswa dinyatakan "tuntas", Berdasarkan pembahasan di atas dan apa yang telah diuraikan pada pembahasan sebelumnya, perangkat pembela-jaran ini dapat disimpulkan memenuhi kategori baik. Sebab keenam syarat terpenuhi: (a) valid berdasarkan penilaian ahli, (b) kemampuan dosen dalam mengelola pembelajaran efektif, (c) aktifitas mahasiswa efektif, (d) respon mahasiswa positif terhadap pembelajaran, dan (e) THB valid, reliable, dan sensitive, (f) hasil belajar mahasiswa secara klasikal tuntas. Oleh karena itu, perangkat pembelajaran filologi berbasis budaya "akasara mbojo" memenuhi kategori "baik".

\section{SIMPULAN}

Berdasarkan tujuan dan hasil penelitian dapat disimpulkan sebagai berikut: 1. Prosedur Perangkat Pembelajaran Model problem Based Learning pada Mata Kuliah Filologi "Naskah Aksara" untuk Melatih Kemampuan Berpikir Kreatif Mahasiswa menggunakan model 4-D yang dimodifikasi menjadi tiga tahap sesuai dengan tujuan penelitian; yaitu: (a) Tahap Pendefinisian. Kegiatan yang dilakukan dalam tahap ini adalah analisis awal-akhir, analisis mahasiswa, analisis konsep, analisis tugas, dan spesifikasi tujuan pembelajaran; (b) Tahap Perancangan. Hasil kegiatan pada tahap ini yaitu rancangan awal perangkat pembelajaran berupa RPS, Worksheet, dan THB; (c) Tahap Pengembangan. Hasil kegiatan pada tahap ini yaitu Draft II, uji keterbacaan menghasilkan Draft III, dan kegiatan akhir yaitu uji coba Draft III, data hasil uji coba dianalisis dan dapat disimpulkan bahwa, perangkat pembelajaran berada pada kategori "baik". 2. Berdasarkan hasil analisis deskriptif, Perangkat Pembelajaran Model problem Based Learning pada Mata Kuliah Filologi "Naskah Aksara"untuk Melatih Kemampuan Berpikir Kreatif Mahasiswa diketegorikan "baik", karena keenam kriteria perangkat pembelajaran yang baik terpenuhi, yaitu: (a) Valid menurut validator, (b) Efektif untuk kemampuan Peneliti/Dosen mengelola pembelajaran, (c) Efektif untuk aktivitas mahasiswa dalam pembelajaran, (d) Positif untuk respon mahasiswa terhadap pembelajaran, (e) Valid, reliabel, dan sensitif untuk THB, dan instrument lainnya

\section{DAFTAR RUJUKAN}

Aries Yuwono. (2012). Program pascasarjana. 2012.

Eshaghi, A., Prados, F., Brownlee, W. J., Altmann, D. R., Tur, C., Cardoso, M. J., De Angelis, F., van de Pavert, S. H., Cawley, N., De Stefano, N., Stromillo, M. L., Battaglini, M., Ruggieri, S., Gasperini, C., Filippi, M., Rocca, M. A., Rovira, A., Sastre-Garriga, J., Vrenken, H., ... Ciccarelli, 0. (2018). Deep gray matter volume loss drives disability worsening in multiple sclerosis. Annals of Neurology, 83(2),

210-222. https://doi.org/10.1002/ana.25145

Fathirma'ruf, B. (2020). PENGEMBANGAN PERANGKAT PEMBELAJARAN KONSTRUKTIVISTIK MODEL TEACHING WITH ANALOGIES ( TWA ) PADA MATAKULIAH DATABASE MANAGEMENT SYSTEM ( DBMS ) UNTUK MENINGKATKAN KEMAMPUAN THE DEVELOPMENT OF CONSTRUCTIVISTIC LEARNING TOOL OF TEACHING WITH ANALOGY ( TWA ). Jurnal Ilmiah Ilmu Pendidikan (JIIP), 7(5), 1051-1060. https://doi.org/10.25126/jtiik.20207238 8

Herlina, Junaidi H. Matsum, H. (2014). Efektivitas Penerapan Model Pembelajaran Berbasis Masalah Dan Peta Konsep Dalam Meningkatkan Hasil Belajar Ekonomi Pada Siswa Kelas Xi Ips. Jurnal Pendidikan Dan Pembelajaran, 3(6), 1-13.

Hutabara, Y., Sarsetyono, Y., \& Apriyanto, N. (2020). Peningkatan PerawatanEngine Konvensional Kijang 5k Melalui Model 
Pembelajaran Problem Based Learning Pada Siswa SMK. Journal of Vocational Education and ..., 1(3).

Mastika Yasa, P. A. E., \& Bhoke, W. (2019). Pengaruh Model Problem Based Learning Terhadap Hasil Belajar Matematika Pada Siswa Sd. Journal of Education Technology, 2(2), 70. https://doi.org/10.23887/jet.v2i2.16184

Nurochmah, A., Sutisnawati, A., \& Wardana, A. E. (2019). Pengelolaan Satuan Pendidikan Dalam Rangka Mencetak Insan Generasi Muda Yang Unggul Di Sekolah Dasar. Holistika: Jurnal Ilmiah PGSD, III(2), 73-80.

Putra, A., Damayanti, P. S., \& Nurahmawati, N. (2021). Hubungan Keterampilan Sosial Terhadap Prestasi Belajar Siswa Kelas IV Sekolah Dasar. Ainara Journal (Jurnal Penelitian Dan PKM Bidang Ilmu Pendidikan), 2(3), 217-221. https://doi.org/10.54371/ainj.v2i3.84

Susila, L. (2021). Pengaruh Metode Latihan High Intensity Interval Training (HIIT) dalam Meningkatkan Power Otot Tungkai dan kelincahan pada Permainan Bola Voli . Ainara Journal (Jurnal Penelitian Dan PKM
Bidang Ilmu Pendidikan),2(3), 230-238. https://doi.org/10.54371/ainj.v2i3.86

Taufik, Erwin, . Husnul Khatimah. (2020). Pengembangan Perangkat Pembelajaran Model CIRC pada Mata Kuliah Apresiasi Sastra " Mantra Mbojo " untuk Melatih Kemampuan Berpikir Kreatif Mahasiswa. Jurnal IImiah Ilmu Pendidikan (JIIP), 3.

Yasin, I. (2021). Problem Kultural Peningkatan Mutu Pendidikan di Indonesia: Perspektif Total Quality Management. Ainara Journal (Jurnal Penelitian Dan PKM Bidang IImu Pendidikan), 2(3), 239-246. https://doi.org/10.54371/ainj.v2i3.87

Yovi Ersariadi1, Hasanuddin2, Z. (2014). Alih Aksara Dan Alih Bahasa Teks Hikayat Si Miskin. Jurnal Bahasa Dan Sastra UNP, 2(2), 83-97. https://doi.org/10.24036/833650

Yusnarti, M., \& Suryaningsih, L. (2021). Pengaruh Model Pembelajaran Role Playing Terhadap Hasil Belajar Siswa Sekolah Dasar. Ainara Journal (Jurnal Penelitian Dan PKM Bidang Ilmu Pendidikan), 2(3), 253-261.

https://doi.org/10.54371/ainj.v2i3.89 